\title{
Development of molecular markers for detecting almond, peanut, pine nut, and walnut in commercial food using quantitative real- time PCR
}

\author{
Ju Hee Kim ${ }^{1}$ Joo Young Hong ${ }^{1} \cdot$ Jun-Cheol Moon ${ }^{2}$ • \\ Kisung Kwon ${ }^{3}$ - Cheol Seong Jang ${ }^{1}$
}

Received: 29 January 2018/Accepted: 26 March 2018/Published online: 7 April 2018

(C) The Korean Society for Applied Biological Chemistry 2018

\begin{abstract}
Nuts have been used globally as health foods. However, because nuts cause allergies, people need to be careful when eating food. Mostly foods are labeled, but sometimes intentional or unintentional mixing might occur. In the present study, we report DNA based on marker for the detection of four nuts almond, peanut, pine nut, and walnut using quantitative real-time polymerase chain reaction (qRT-PCR). Species-specific primer sets for four species were designed based on the single-nucleotide polymorphisms and insertion/deletion of the chloroplast gene, matK. The sensitivity of primer sets for the four species studied was assessed by analyzing DNA dilutions at concentration of $0.001-10 \mathrm{ng}$ and binary mixtures of $0.1-100 \%$ of heat-treated and non-heat-treated samples. The four primer sets developed in the present study indicated appropriate amplification efficiency and correlation coefficients of the standard curves. In addition, to verify the applicability of these molecular markers, we performed a qRT-PCR with 14 commercial products and successfully detected the matK genes in several commercial food products that were declared to contain nuts. Thus, markers
\end{abstract}

Cheol Seong Jang

csjang@kangwon.ac.kr

1 Plant Genomics Lab, Department of Bioresource Sciences, Kangwon National University, Chuncheon 24341, Republic of Korea

2 Agriculture and Life Sciences Research Institute, Kangwon National University, Chuncheon 24341, Republic of Korea

3 New Hazardous Substance Team, Food Safety Evaluation Department, National Institute of Food and Drug Safety Evaluation, Ministry of Food and Drug Safety, 187 Osongsaengmyeong 2-ro, Osong-eup, Heungdeok-gu, Cheongju-si, Chungcheongbuk-do 28159, Republic of Korea developed could be useful tools for confirming the presence of the four nut species in commercial products.

Keywords Almond - Commercial products · DNA-based marker · Peanut · Pine nut - Quantitative real-time polymerase chain reaction . Walnut

\section{Introduction}

Because nuts contain abundant essential fatty acids, vegetable protein, and vitamin E, they are well recognized as health foods for a long time. Particularly almond (Prunus dulcis), peanut (Arachis hypogaea), pine nut (Pinus koraiensis), and walnut (Juglans regia) are generally known to contain more than $50 \%$ fat and are considered to prevent heart disease, dementia, aging, and cancer [1,2]. However, because these four species of nuts cause allergies, their potential health benefits do not apply to everyone, and people sensitive to them need to be careful when consuming them. Almonds are known to cause an abnormal immunological response, the intensity of which ranges from mild reactions to fatal anaphylactic shock even when only minimal doses are consumed [3]. Presently, eight groups of allergenic proteins in almonds have been identified and characterized. These are PR-10 (Pru du 1), TLP (Pru du 2), prolamins (Pru du 2S albumin and Pru du 3), profilins (Pru du 4), 60sRP (Pru du 5), and cupin (Pru du 6 and Pru du $\gamma$-conglutin) [4]. Peanuts are also known to be the most allergenic foods in the world. Peanut-induced anaphylaxis is an IgE-mediated reaction to allergens in peanuts. Currently, eight peanut allergens (Ara h1 to h8) have been identified. Peanut-induced anaphylaxis is estimated to affect 1.5 million people in the USA and cause the 
death of 50-100 people each year [5]. Pine nuts allergens with IgE-binding properties have been investigated in several studies, but official allergen names have not been registered. Furthermore, it is known that allergic reactions to pine nuts can be stimulated by certain drugs. In fact, a patient with no previous history of allergies, who was diagnosed with hypertension, experienced severe anaphylactic shock after eating food containing pine nuts [6]. In walnuts, allergens are grouped into three protein families, namely the prolamins (Jug r 1, Jug n 1, and Jug r 3), the cupins (Jug r 2, Jug n 2, and Jug r 4), and the profilins (Jug r 5) [7]. Symptoms of an allergic reaction to walnuts appear immediately after consumption and range from mild, such as skin reactions, to severe, such as breathing difficulties. Although some studies estimating the occurrence of nut allergies have been conducted, information on the incidence of specific nut allergies is still very scarce. Additionally, no cure has been found for allergies, and strict avoidance of nuts is the only way to prevent severe symptoms. Food allergies have become a serious health problem in many countries, and they have been selected by the World Health Organization (WHO) as the sixth issue of human health [8]. Since 1990, the number of people suffering from allergic reactions has increased drastically. In the UK, 1.5 million people are affected by allergies and 10-20 people are estimated to die each year owing to allergies [9]. People with allergies can suffer owing to the presence of nuts in their diet. There are serious recognized social and medical problems that can reduce the quality of life. For example, the European Union, the USA, and Canada have regulated labeling of food allergens [8].

Various assays for the detection of contamination with nut in commercial products have been reported over the last decade. These methods have targeted the allergen itself, compounds, marker proteins, or DNA fragments. Typically, one of the protein-based assays is an enzymelinked immunosorbent assay (ELISA), which quantitatively measures antigens based on the intensity of antigenantibody interactions, with enzyme activity as an indicator [10]. In addition, DNA-based assay is a method of amplifying only a part of target DNA sequences for the detection of food ingredients. In particular, real-time polymerase chain reaction (RT-PCR) is known to be a simple, fast, and accurate method, which is more economical than the other assays. In addition, its application extends to various fields, such as genetic analysis, virus testing, and DNA sequence analysis. Another attractive advantage is that it can be amplified even with a small amount of DNA, which is useful for identifying species in processed foods [11, 12]. For instance, several studies have reported successful identification of nut species, such as almonds [13], walnuts [14], cashew nuts [15], Brazil nuts [8], and hazelnuts [16] using quantitative real-time polymerase chain. This method has been successfully applied to nuts, in addition to other plant species such as sesame [17], coffee [18], celery [19], rice [20], and the medicinal herb Cynanchum wilfordii [21].

Chloroplasts are plant and algal cell organelles, and their function is to conduct photosynthesis. The chloroplast DNA is a single circular molecule, and chloroplast genome size varies among species, ranging from 107 to $218 \mathrm{~kb}$ [22]. It is generally believed that chloroplast genome possesses 120-130 genes. Among them, several genes such as $m a t K, n d h F, y c f l$, and ccsA evidenced higher frequencies of single-nucleotide polymorphisms and insertion/ deletions (InDels) than the average [22]; therefore, these genes have been used for species identification. In particular, the sequence of mat $K$ encoding the maturase involved in type II intron splicing is often used for phylogenetic and evolutionary studies [23, 24]. In a previous study, we developed species-specific molecular markers using singlenucleotide polymorphisms (SNPs) of matK genes and successfully applied the markers to commercial food [21]. In the present study, we reported the development of molecular markers and optimization of an qRT-PCR system using SYBR green and SNPs of $m a t K$ genes for species identification of nuts, including almonds, peanuts, pine nuts, and walnuts, which are known as food allergens. Therefore, the applicability of the chloroplast DNA (cpDNA) markers developed was evaluated with 14 commercial food products.

\section{Materials and methods}

\section{Sample preparation and total genomic DNA extraction}

For standard sample preparation, plants of almond, peanut, pine nut, and walnut were purchased from the Korea plant nursery (https://seedling.kr/). The plants were grown in a growth chamber at $25{ }^{\circ} \mathrm{C}$ with a photoperiod of $16 \mathrm{~h}: 8 \mathrm{~h}$ (light/dark) and $70 \%$ humidity before DNA extraction. Fourteen commercial products, such as powder, nut bar, and tea, were purchased from local markets (Table 1).

Total genomic DNA was extracted from $100 \mathrm{mg}$ of each leaf sample using the i-genomic Plant DNA Extraction Mini Kit (iNtRON Biotechnology, Seongnam, Korea) according to the manufacture's protocol. For DNA extractions from commercial products and de-shelled nuts, a modified cetyltrimethylammonium bromide (CTAB) method $(100 \mathrm{mM}$ Tris $\mathrm{pH} 7.5,700 \mathrm{mM} \mathrm{NaCl}, 10 \mathrm{mM}$ EDTA, $1 \%$ CTAB, $1 \% \beta$-mercaptoethanol) was used, according to Valdivia and Burns [25]. One gram of each of the ground samples was mixed with $10 \mathrm{~mL}$ of $\mathrm{CTAB}$ buffer and $30 \mu \mathrm{L}$ of proteinase $\mathrm{K}(20 \mathrm{mg} / \mathrm{mL})$ (Sigma- 
Table 1 Food materials of 14 commercial products used in this study

\begin{tabular}{|c|c|c|c|}
\hline \multirow{2}{*}{$\begin{array}{l}\text { Food } \\
\text { markers }\end{array}$} & \multirow[t]{2}{*}{ Product name } & \multicolumn{2}{|l|}{ Material components } \\
\hline & & Major component $(\%)$ & Minor component \\
\hline A & $\begin{array}{l}\text { Roasted and ground } \\
\text { walnut }\end{array}$ & Walnut (100) & \\
\hline B & & Peanut (100) & \\
\hline $\mathrm{C}$ & & Almond (100) & \\
\hline $\mathrm{D}$ & & Pine nut (100) & \\
\hline $\mathrm{E}$ & Chocolate almond & $\begin{array}{l}\text { Almond (7), grape (3.6), jujube (5.4), peanut (42), sunflower seed } \\
\text { (1.8) }\end{array}$ & \\
\hline $\mathrm{F}$ & Yogurt fruits \& nuts & $\begin{array}{l}\text { Apricot (6), grape (10), jujube (4), peanut (37), pumpkin seed } \\
(1.2) \text {, sunflower seed (1.6) }\end{array}$ & Wheat \\
\hline G & $\begin{array}{l}\text { Mega nut double } \\
\text { choco }\end{array}$ & Peanut (48), rice (12.6) & \\
\hline $\mathrm{H}$ & Crunchy nut bar & Almond (18.5), cashew nut (32) & $\begin{array}{l}\text { Mango, papaya, pineapple, peanut, rice, } \\
\text { sesame, sorghum, sunflower seed }\end{array}$ \\
\hline I & Tropical nut bar & Almond (15), cashew nut (32) & $\begin{array}{l}\text { Cranberry, mango, papaya, peanut, } \\
\text { pineapple, pumpkin seed, sesame, } \\
\text { sunflower seed }\end{array}$ \\
\hline $\mathrm{J}$ & Nut bar-Amaranth & $\begin{array}{l}\text { Almond (18.8), amaranth (1.1), cashew nut (4), peanut (33.7), } \\
\text { walnut ( } 2 \text { ) }\end{array}$ & Cranberry \\
\hline K & Nut bar-Fig & Almond (19), cashew nut (4.3), fig (3.8), peanut (34.3), walnut (2) & \\
\hline $\mathrm{L}$ & $\begin{array}{l}\text { Nut bar-Fruit \& } \\
\text { Quinoa }\end{array}$ & $\begin{array}{l}\text { Almond (3.8), blueberry (11), cashew nut (8.9), cherry (5.6), fig } \\
\text { (20), grape }(8.1) \text {, pumpkin seed (11), sunflower seed (3.8), } \\
\text { quinoa (1.3) }\end{array}$ & \\
\hline M & $\begin{array}{l}\text { Walnuts, almonds, } \\
\text { pine nuts and } \\
\text { adlay tea }\end{array}$ & Adlay (1), almond (4), pine nut (1), walnut (1) & Maize, peanut, pumpkin seed, rice \\
\hline $\mathrm{N}$ & $\begin{array}{l}\text { Walnuts, almonds } \\
\text { and adlay tea }\end{array}$ & Adlay (1), almond (4), walnut (3) & Peanut, pine nut \\
\hline
\end{tabular}

Aldrich, Saint Louis, MO, USA), followed by incubation at $65{ }^{\circ} \mathrm{C}$ overnight. The mixtures were centrifuged at $4000 \times g$ for $10 \mathrm{~min}$. The supernatant was transferred to a $1.5-\mathrm{mL}$ tube and centrifuged again at $14,000 \times g$ for $5 \mathrm{~min}$. The supernatant was mixed with a mixture of chloroform/ isoamyl alcohol $(24: 1)$ and centrifuged at $16,000 \times g$ for $15 \mathrm{~min}$. The supernatant was transferred to a new $1.5-\mathrm{mL}$ tube and added pre-cooled $\left(-20^{\circ} \mathrm{C}\right)$ isopropanol. The mixture was incubated at room temperature for $30 \mathrm{~min}$ and then centrifuged at $16,000 \times g$ for $20 \mathrm{~min}$. The pellet was washed with $70 \%$ pre-cooled ethanol and centrifuged at $7500 \times g$ for $5 \mathrm{~min}$. The ethanol was discarded and the pellet dried at room temperature for $15 \mathrm{~min}$. The dried pellets with high lipid content were further purified using the Wizard ${ }^{\circledR}$ DNA Clean-Up System (Promega, Madison, WI, USA) according to the manufacture's protocol. Yield of the extracts were assessed using a Qubit ${ }^{\circledR}$ 2.0 Fluorometer (Invitrogen, Life Technologies, Grand Island, NY, USA) and measured the ratio of the absorbance at 260 and $280 \mathrm{~nm}\left(A_{260 / 280}\right)$. Their purifies were confirmed using agarose gel electrophoresis with a Molecular Imager ${ }^{\circledR} \mathrm{Gel}$
$\mathrm{DOC}^{\mathrm{TM}} \mathrm{XR}+$ System (Bio-Rad ${ }^{\mathrm{TM}}$, Hercules, CA, USA), and BioPhotometer Plus UV/Vis Photometer (Eppendorf, Westbury, NY, USA).

\section{Sequence analysis and primer design}

In order to design primer pairs, the chloroplast matK DNA sequences of four nut species, including almond, peanut, pine nut, and walnut, were downloaded from the database of the National Center for Biotechnology Information (NCBI, https://www.ncbi.nlm.gov/). The lengths of matK (partial or complete) in almond (accession number AF288115), peanut (EU307349), pine nut (AB161009), and walnut (KC920677) were 1521, 635, 1661, and 726 bp, respectively. The partial or complete sequence was aligned using ClustalW2 program (ftp://ebi.ac.uk/pub/software/ clustalw2/) to compare differences among the matK gene of the four species. Thereafter, species-specific primers were designed based on the SNP and InDels, and they were synthesized using a commercial service (Macrogen, Seoul, Korea). 


\section{Quantitative real-time PCR}

A CFX Connect ${ }^{\mathrm{TM}}$ Real-Time PCR Detection System (Bio-Rad ${ }^{\mathrm{TM}}$, Hercules, CA, USA) was used to perform qRT-PCR. The reaction mixture contained $10 \mathrm{ng} / \mu \mathrm{L}$ of DNA, $10 \mu \mathrm{L}$ of SYBR ${ }^{\circledR}$ Green TOP real qPCR $2 X$ PreMIX (Enzynomics ${ }^{\mathrm{TM}}$, Daejeon, Korea), and 10 pmol each primer in a final volume of $25 \mu \mathrm{L}$. All qRT-PCRs were carried out in triplicate. The amplification condition was as follows: $10 \mathrm{~min}$ at $95^{\circ} \mathrm{C}$, followed by 40 cycles of $10 \mathrm{~s}$ at $95{ }^{\circ} \mathrm{C}, 30 \mathrm{~s}$ at $54-56{ }^{\circ} \mathrm{C}$, and $20 \mathrm{~s}$ at $72{ }^{\circ} \mathrm{C}$. The amplification program was then followed by a melting cycle of $95{ }^{\circ} \mathrm{C}$ for $10 \mathrm{~s}, 65^{\circ} \mathrm{C}$ for $5 \mathrm{~s}$, and slow heating to $95^{\circ} \mathrm{C}$ for $0 \mathrm{~s}$, with a temperature increment of $0.5{ }^{\circ} \mathrm{C}$ every $5 \mathrm{~s}$.

\section{Construction of the standard curve and data analysis}

In order to evaluate the linear correlations of the four nut species studied (almond, peanut, pine nut, and walnut), dilution series of DNA $(0.001,0.05,0.01,0.5,0.1,1,5$, and $10 \mathrm{ng}$ ) of each species was used. In order to estimate the presence of target species in commercial products, standard curves were constructed using binary mixtures of heat treatment $\left(121^{\circ} \mathrm{C}\right.$ and $152 \mathrm{kPa}$ for $\left.15 \mathrm{~min}\right)$ and non-heat treatment containing different ratios $(0.1,1,10$, and $100 \%)$.

Correlation coefficient $\left(R^{2}\right)$ using the liner regression method $\left(R^{2} \geq 0.98\right)$ [26] and the slope of standard curve (range from -3.6 to -3.1 ) [27] were used as parameters for evaluating the efficiency of the primers. The amplification efficiency, $E$, was determined from the slope of the standard curve using the following formula [28]: $E=10^{-1 /}$ slope and $E(\%)=(E-1) \times 100$. The coefficient of variation is presented as a percentage and was calculated from the average and standard deviation as follows: [Standard Deviation (SD)/Average] $\times 100$.

\section{Results and discussion}

\section{Development of chloroplast DNA markers for nut}

We had aimed at developing molecular markers that can detect four nut species almond, peanut, pine nut, and walnut. In previous studies, the matK gene was widely used for phylogenetic and evolutionary analysis due to its diversity among species [29-31]. We analyzed the nucleotide sequence alignments and confirmed the presence of nucleotide polymorphisms in the matK gene among the four species studied (Fig. 1A). Based on the SNP and InDels, the primer sets were designed to amplify the DNA of the target species in the matK gene. Each of the arrows in Fig. 1A represents the primer positions of the target species (red-almond; blue-pine nut; green-walnut; yellow-peanut), and four pairs of primers corresponding to the nucleotide sequences were designed for qRT-PCR analysis (Table 2). In addition, to evaluate the specificity of PCR amplification, the species-specific primer sets were used for amplification in end-point PCR (30 cycles) and the products were visualized by agarose gel electrophoresis (Fig. 1C). The PCR products amplified were of the desired size in the genomic DNA of almond (115 bp), peanut (75 bp), pine nut (97 bp), and walnut (165 bp) (Fig. 1B). In addition, we analyzed the melting peaks of the amplification products, which revealed differences between the target and non-target species. Amplification using the species-specific primer sets resulted in sharp peaks for the target species but not for the non-target species (Fig. 2). These results indicated that each primer set was amplified only in the target species, and that no cross-amplification occurred in the non-target species. These findings suggest that species-specific primer sets could be used to distinguish between four different plant species.

\section{Evaluation of amplification efficiency of four markers using SYBR green}

In order to evaluate the sensitivity and efficiency of the developed primers, we prepared standard curves using the DNA dilution series and performed regression analysis. Total genomic DNA was extracted from leaves of each target species and used for qRT-PCR analysis. The correlation coefficient $\left(R^{2}\right)$ was higher than 0.98 for all primer sets, and slope was -3.48 for almond, -3.66 for peanut, -3.77 for pine nut, and -3.58 for walnut, respectively (Fig. 3). Based on the slope, the efficiency was calculated as $93.94 \%$ for almond, $87.59 \%$ for peanut, $84.20 \%$ for pine nut, and $90.40 \%$ for walnut, respectively (Fig. 3). However, as compared with the target species, the non-target species were amplified with a $C_{\mathrm{p}}$ value higher than 30 (Fig. 3). We also sequenced the qRT-PCR products to confirm that the target genes were amplified accurately. Sequence analysis using the ClustalW2 program showed that the sequenced qRT-PCR product and the reference sequence were perfectly matched (Fig. 4). These results indicate that all four primer sets (almond, peanut, pine nut, and walnut) could be used to identify species under appropriate amplification conditions using more than $1 \mathrm{pg}$ of DNA and a $C_{\mathrm{p}}$ value of less than 30 . The species-specific primer sets, designed according to the MIQR guidelines [28], had an appropriate $R^{2}$ value $(\geq 0.98)$ and slope (3.6-3.1). The validity of using these primers was confirmed through the construction of a standard curve. Lastly, sequencing the PCR products confirmed that the target gene was amplified from the desired target species. 
(A)
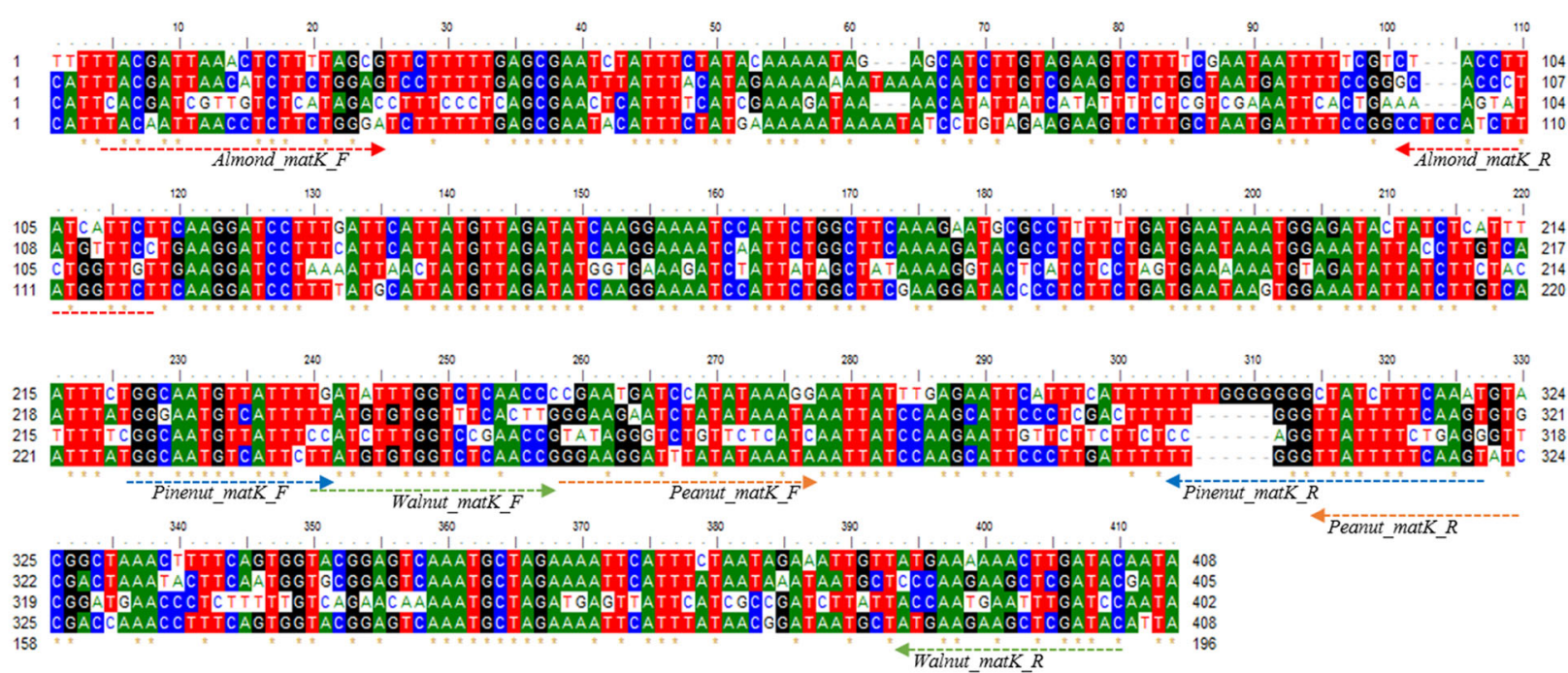

(B)
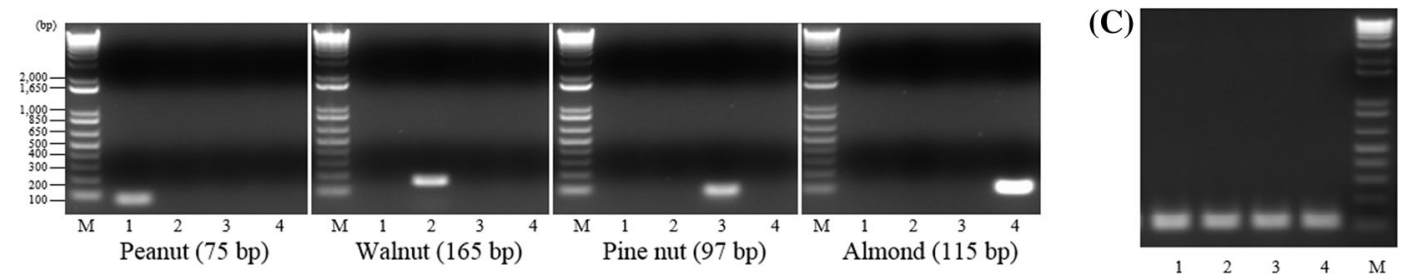

Fig. 1 Alignment of matK gene sequences Arachis hypogaea (peanut), Juglans regia (walnut), Pinus koraiensis (pine nut), Prunus dulcis (almond) using Clustal W2 program (A). Species-specific primer sets were indicated by arrows. Yellow for peanut; green for walnut; blue for pine nut; red for almond. PCR products (30 cycles) were electrophoresed to confirm cross-reactivity (B). All the DNA samples extracted from the leaf samples were subjected to $18 \mathrm{~S}$ rRNA amplification (C). M; 1 kb Plus DNA ladder marker, Lanes 1 peanut; Lanes 2 walnut; Lanes 3 pine nut; Lanes 4 almond

Table 2 Information of primer sets used in this study

\begin{tabular}{|c|c|c|c|c|c|}
\hline Species & Primers & Sequences $\left(5^{\prime} \rightarrow 3^{\prime}\right)$ & Target gene & Amplicons (bp) & References \\
\hline \multirow[t]{2}{*}{ Arachis hypogaea } & Peanut_matK_F $F^{\mathrm{a}}$ & CGA ATG ATC CAT ATA AAG G & & 75 & \\
\hline & Peanut_matK_R $R^{\mathrm{b}}$ & CCG TAC ATT TGA AAG ATA G & & & \\
\hline \multirow[t]{2}{*}{ Juglans regia } & Walnut_matK_F & TTA TGT GTG GTT TCA CTT & & 165 & \\
\hline & Walnut_matK_R & GTA TCG AGC TTC TTG GG & matK & & This work \\
\hline \multirow[t]{2}{*}{ Pinus koraiensis } & Pinenut_matK_F & TCG GCA ATG TTA TTT CC & & 97 & \\
\hline & Pinenut_matK_R & CCT CAG AAA ATA ACC TGG & & & \\
\hline \multirow[t]{2}{*}{ Prunus dulcis } & Almond_matK_F & TAC AAT TAA CCT CTT CTG GG & & 115 & \\
\hline & Almond_matK_R & AAG AAC CAT AAG ATG GAG G & & & \\
\hline \multirow[t]{2}{*}{ Plant system } & 18S rRNA_F & TCT GCC CTA TCA ACT TTC GAT GGT A & $18 S r R N A$ & 137 & {$[32]$} \\
\hline & 18S rRNA_R & AAT TTG CGC GCC TGC TGC CTT CCT T & & & \\
\hline
\end{tabular}

${ }^{\mathrm{a}}$ Forward primer

${ }^{\mathrm{b}}$ Reverse primer

Because heat treatment is essential for food processing, the primer sets were first tested on heat-treated or non-heattreated samples before application to commercial products. Samples for heat/non-heat treatment were prepared as a binary mixture containing a different percentage of wheat flour and ground nut material $(0.1,1,10$, and 100\%). The heat treatment of de-shelled nut was carried out using an autoclave with treatment condition $121{ }^{\circ} \mathrm{C}$ and $152 \mathrm{kPa}$ for $15 \mathrm{~min}$. Total genomic DNA was extracted from samples subjected to heat treatment/non-heat treatment using a modified CTAB method, and qRT-PCR analysis was performed. In the non-heat treatment, the samples had an $R^{2}$ 
(A)

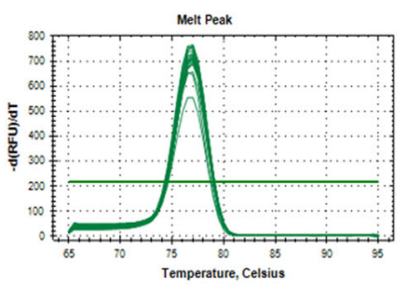

(B)

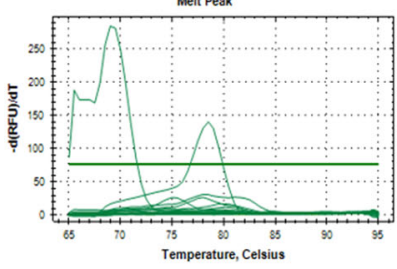

(C)

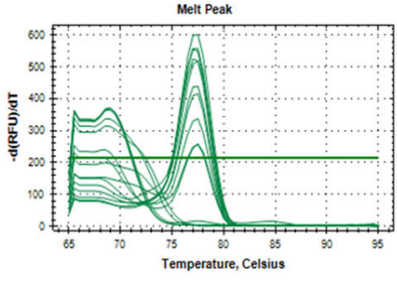

(D)

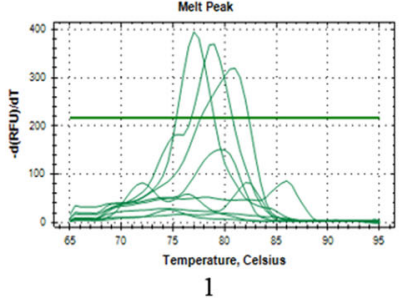

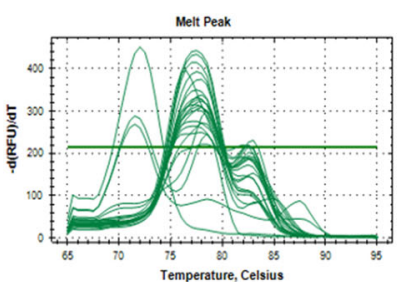

Melt Peak

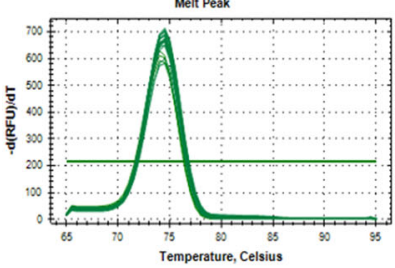

Melt Peak

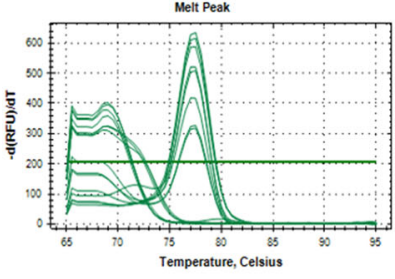

Melt Peak

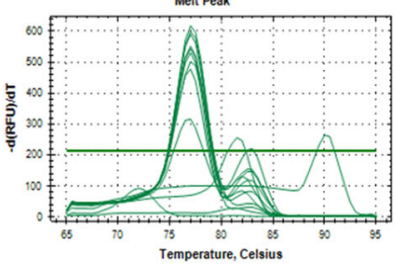

2

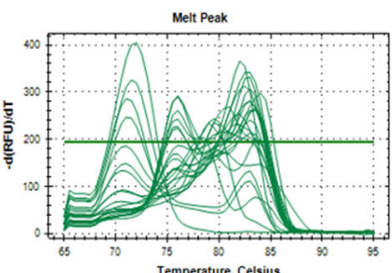

Melt Peak

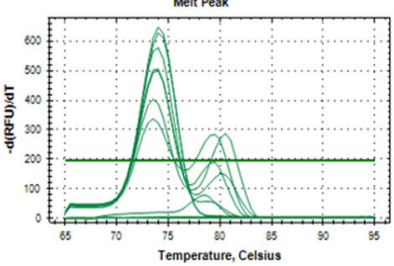

Melt Peak

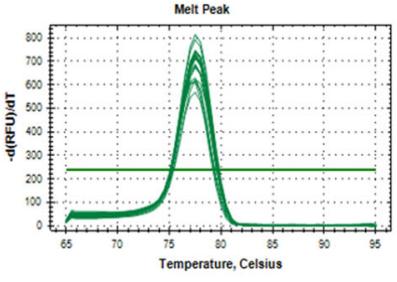

Melt Peak

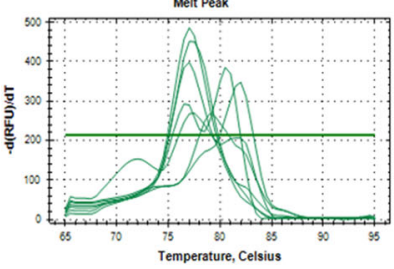

3

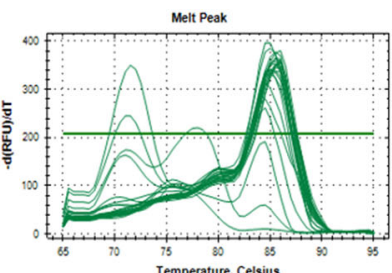

Melt Peak

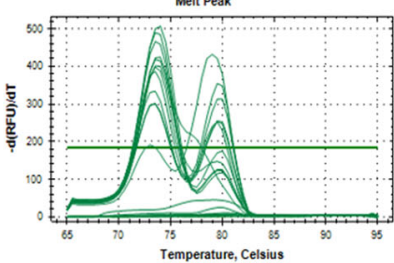

Melt Peak

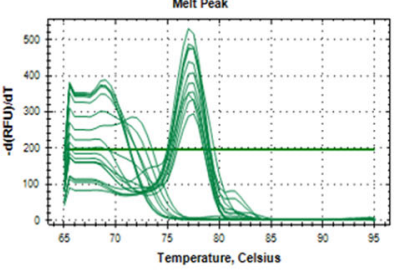

Melt Peak

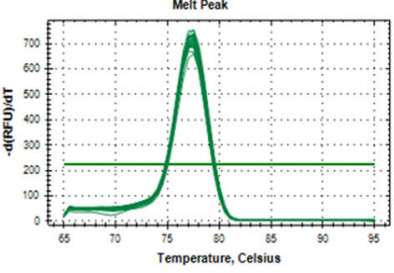

4
Fig. 2 Melting curve analysis and difference curves of the matK genes amplicons from the four primer sets. Almond-specific primer (A), peanut-specific primer (B), pine nut-specific primer (C), and walnut-specific primer (D). Lanes 1 diluted almond DNA; Lanes 2

value higher than 0.97 for all primer sets, and slope value was -3.87 for almond, -3.76 for peanut, -3.84 for pine nut, and -3.91 for walnut, respectively (Fig. 5A). The calculated efficiency based on the slope was $93.91 \%$ for almond, $110.52 \%$ for peanut, $88.80 \%$ for pine nut, and $89.47 \%$ for walnut, respectively (Fig. 5A). The heat-treated samples had an $R^{2}$ value higher than 0.99 for all primer sets, and the slope was -3.48 for almond, -3.09 for peanut, -3.62 for pine nut, and -3.60 for walnut, respectively (Fig. 5B). The calculated efficiency based on the slope was $81.39 \%$ for almond, $84.41 \%$ for peanut, $82.08 \%$ for pine nut, and $80.31 \%$ for walnut, respectively (Fig. 5B). These results suggested that the developed species-specific primer sets for almond, peanut, pine nut, and walnut could detect up to $0.1 \%$ in heat-treated or non-heattreated DNA in a binary mixture. diluted peanut DNA; Lanes 3 diluted pine nut DNA; Lanes 4 diluted walnut DNA. qRT-PCRs were carried out in triplicate PCR reactions. All non-target species amplified with $C_{\mathrm{p}}$ value higher than 30 and constructed non-specific melting peaks

\section{Application of developed cpDNA markers to commercial food products}

To verify the applicability of the four species-specific primer sets developed, 14 commercial products we purchased from local markets and examined. This confirmation procedure is essential to protect allergy-sensitive consumers from intentional or unintentional mixing of nuts, because nuts can contain allergenic ingredients. Fourteen commercial products for qRT-PCR analysis included four simple processing products (powders), eight nut bars, and two teas. The accurate detection of allergens in simple processed foods (tea and powder) as well as foods that have undergone complex processing steps (chocolate and nut bars) depends on reliable DNA extraction prior to qRT-PCR analysis. In general, it is difficult to extract high-quality DNA (high concentration and purity) from nuts with a high-fat content using commercial kits and general CTAB methods (Fig. 6A). However, using the modified CTAB method described by Valdivia and Burns [25], we were able to effectively increase the DNA 
(A) Almond

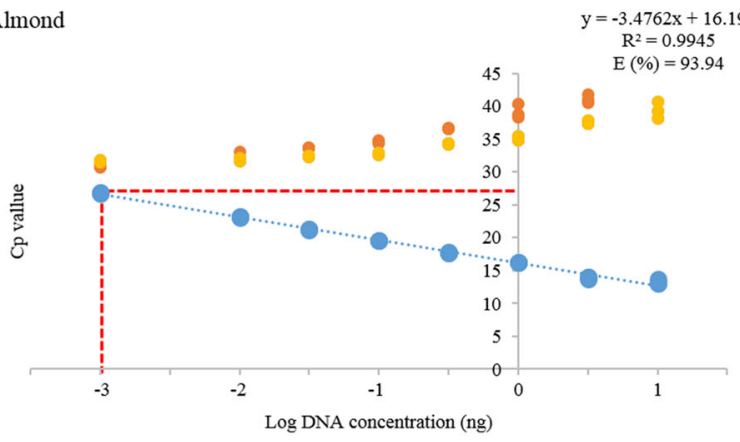

(B) Peanut

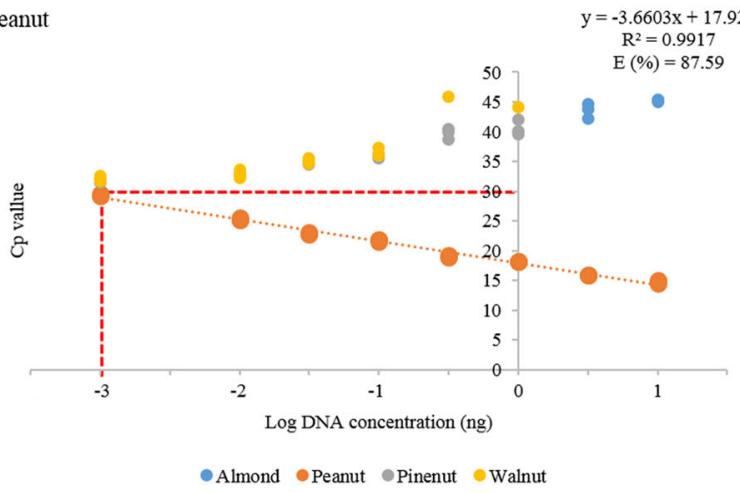

Fig. 3 Standard curves obtained by analyzing serially diluted DNA of almond (A), peanut (B), pine nut $(\mathbf{C})$, and walnut (D), respectively. The red dotted line indicates the $C_{\mathrm{p}}$ value that distinguishes the target
(C) Pine nut

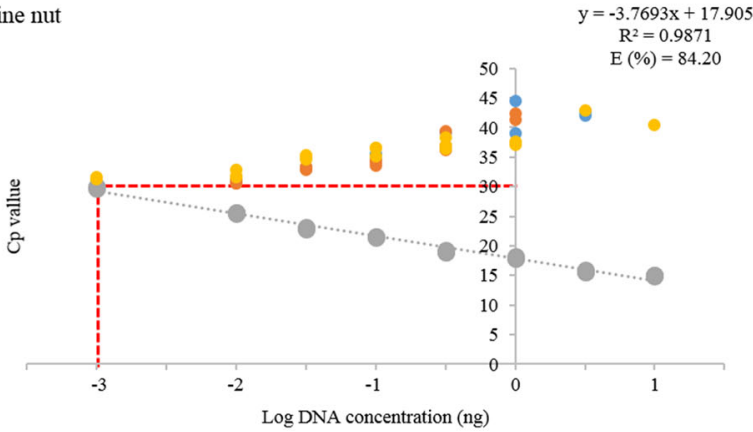

(D) Walnut

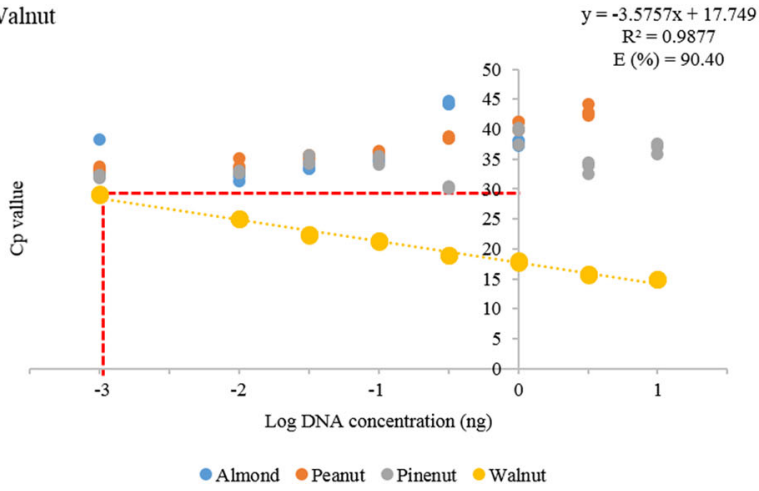

species from non-target species. The qRT-PCRs were carried out in triplicate. The $X$-axis represents $\log$ (DNA concentration), and the $Y$ axis represents $C_{\mathrm{p}}$ value

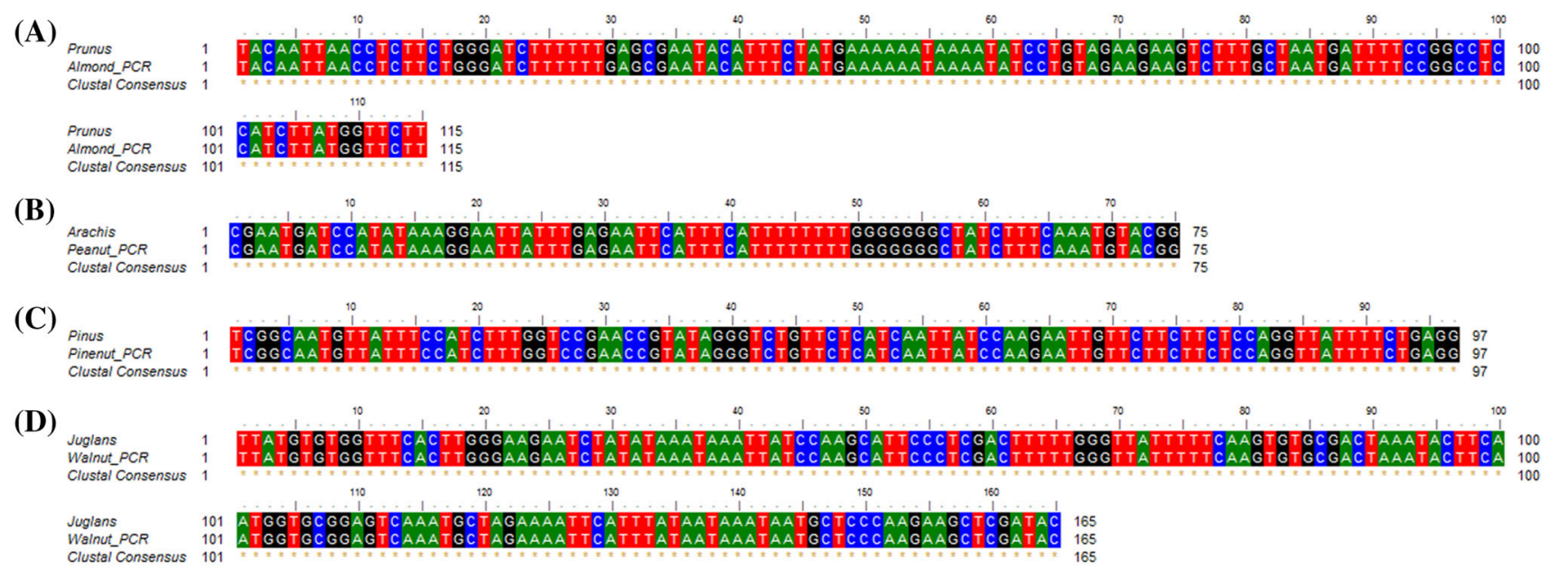

Fig. 4 The sequencing results of PCR products with a reference sequence using the ClustalW2. (A) Almond; (B) peanut; (C) pine nut; (D) walnut

extraction efficiency (Fig. 6B). The DNA extracted from the 14 commercial food products using the modified CTAB method was then analyzed by qRT-PCR using the four species-specific primer sets. The presence of the extracted DNA was confirmed by amplifying the $18 \mathrm{~S}$ rRNA gene as a positive control (Table 3) [32]. We carried out qRT-PCR analysis on different types of commercial products using species-specific primer pairs to detect the presence of almonds, peanuts, pine nuts, and walnuts in the products and compared the detection results with the ingredients indicated on the labels of the 14 commercial food products. The analysis successfully detected almonds in 10 out of 10 samples, peanuts in 9 out of 10 samples, pine nuts in 1 out of 2 samples, and walnuts in 5 out of 5 samples (Table 3 ). However, even though food sample $\mathrm{N}$ (walnuts, almonds, and adlay tea) was labeled as containing almonds, peanuts, 
(A)

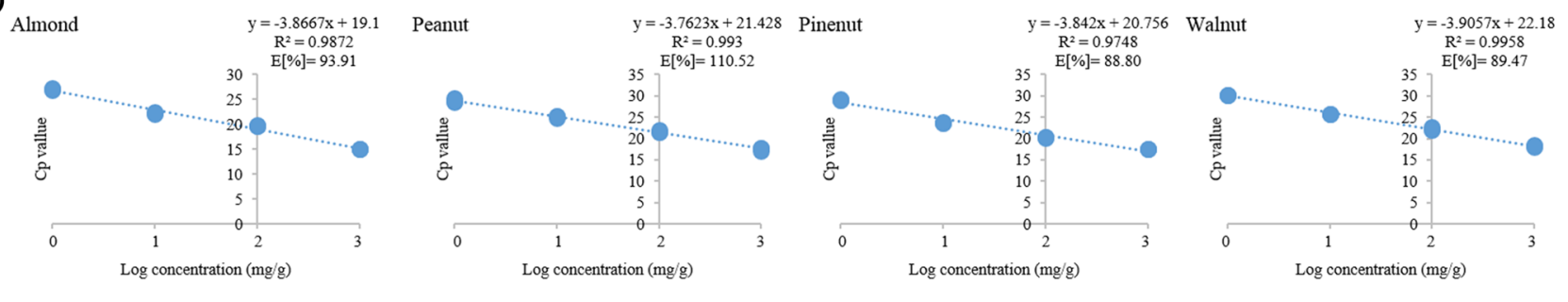

(B)
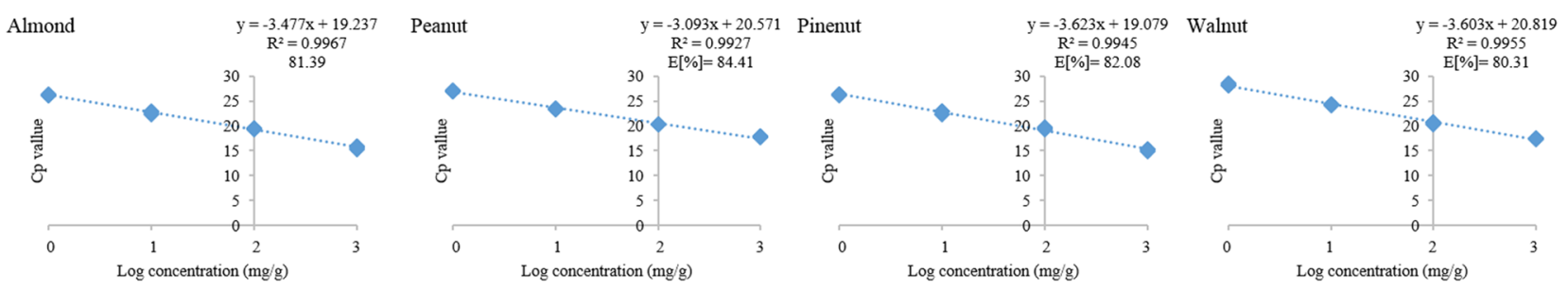

Fig. 5 Standard curves based on binary mixture of wheat flour and almond, peanut, pine nut, or walnut, respectively. The standard curves were obtained from the non-heat-treated binary mixture (A), and heat-

treated $\left(121{ }^{\circ} \mathrm{C}\right.$ and $152 \mathrm{kPa}$ for $\left.15 \mathrm{~min}\right)$ binary mixture (B). The qRT-PCRs were carried out in triplicate. The $X$-axis represents $\log$ (DNA concentration), and the $Y$-axis represents $C_{\mathrm{p}}$ value
Fig. 6 Total genomic DNA extracted from 14 commercial products (Table 1); CTAB

(A) and modified CTAB

(B) methods. M; 1 kb Plus DNA ladder marker (Invitrogen), Lanes A-N; total genomic DNA from 14 commercial products
(A)

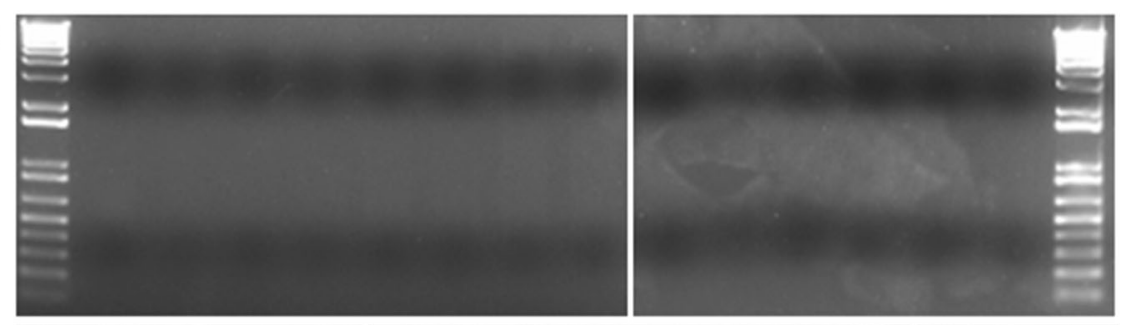

(B)
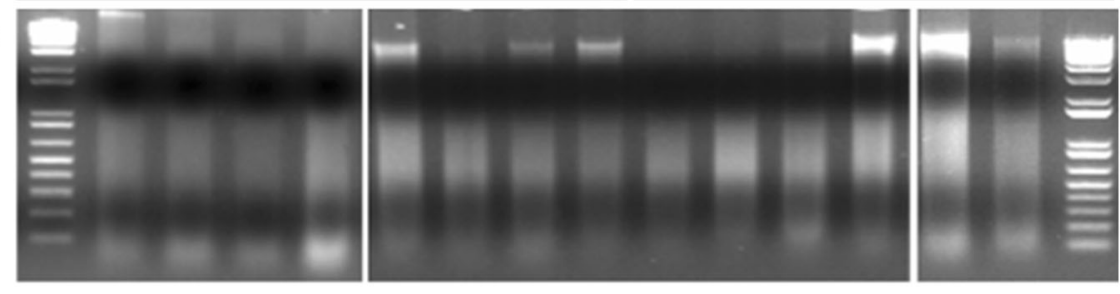

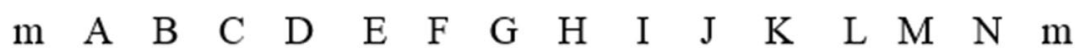

pine nuts, and walnuts, pine nuts were not detected. Our results for most commercial products, except food sample $\mathrm{N}$, were consistent with the indicated ingredients, suggesting that the primer sets could be used to detect processed nuts containing allergens in commercial foods. However, some food samples showed inconsistencies between a major (or minor) ingredient labeling and the analysis results. These inconsistencies may result because of DNA damage during food processing or mislabeled food samples.

In previous studies, various approaches were used to detect nuts such as ELISA and PCR-based methods. The ELISA method was used to detect Brazil nut in food products [33] and widely used in various diagnostic tests and plant pathology $[34,35]$. The PCR-based methods have been used as the most common method for identifying target species in commercial products. For example, Yano et al. [36] reported the detection of walnut using a single PCR method, and Renčová et al. [37] reported peanut and hazelnut detection using a multiplex PCR method. However, the results of these methods depend on the composition of the buffer or the antigen, and performing them requires expert skill, and because previously developed methods have not been evaluated for sensitivity, specificity, and efficiency, their application in target species identification in commercial products can be difficult. For example, Linacero et al. [14] reported detection of walnut allergen-coding sequences in processed foods based on qRT-PCR using SYBR green. Iniesto et al. [37] reported primer sets for the detection of allergen-coding sequences 
Table 3 Results of the analysis of 14 commercial products using almond, peanut, pine nut, and walnut primer sets

\begin{tabular}{|c|c|c|c|c|c|c|c|c|c|c|}
\hline $\begin{array}{l}\text { Type of commercial } \\
\text { products }\end{array}$ & $\begin{array}{l}\text { Food } \\
\text { markers }\end{array}$ & P.A.C ${ }^{a}$ & Almond & $\begin{array}{l}\mathrm{CV}^{\mathrm{b}} \\
(\%)\end{array}$ & Peanut & $\begin{array}{l}\mathrm{CV} \\
(\%)\end{array}$ & Pine nut & $\begin{array}{l}\mathrm{CV} \\
(\%)\end{array}$ & Walnut & $\begin{array}{l}\mathrm{CV} \\
(\%)\end{array}$ \\
\hline \multirow{4}{*}{$\begin{array}{l}\text { Nuts and roasted } \\
\text { (Powder) }\end{array}$} & $\mathrm{A}$ & $12.92 \pm 0.17$ & $-^{\mathrm{c}}$ & & - & & - & & $15.09 \pm 0.21$ & 1.36 \\
\hline & $\mathrm{B}$ & $14.75 \pm 0.26$ & - & & $18.71 \pm 0.36$ & 0.13 & - & & - & \\
\hline & $\mathrm{C}$ & $12.95 \pm 0.20$ & $15.74 \pm 0.01$ & 0.76 & - & & - & & - & \\
\hline & $\mathrm{D}$ & $13.70 \pm 0.11$ & - & & - & & $14.69 \pm 0.39$ & 0.79 & - & \\
\hline \multirow[t]{8}{*}{ Nut bar } & $\mathrm{E}$ & $13.89 \pm 0.15$ & $34.05 \pm 0.33$ & 0.98 & $22.40 \pm 0.42$ & 1.86 & - & & - & \\
\hline & $\mathrm{F}$ & $15.32 \pm 0.04$ & - & & $21.40 \pm 0.01$ & 0.07 & - & & - & \\
\hline & $\mathrm{G}$ & $11.13 \pm 0.10$ & - & & $21.01 \pm 0.29$ & 1.38 & - & & - & \\
\hline & $\mathrm{H}$ & $17.05 \pm 0.14$ & $21.69 \pm 0.11$ & 0.49 & $19.54 \pm 0.36$ & 1.85 & - & & - & \\
\hline & I & $16.25 \pm 0.23$ & $17.56 \pm 0.11$ & 0.60 & $32.31 \pm 0.10$ & 0.31 & - & & - & \\
\hline & $\mathrm{J}$ & $16.53 \pm 0.10$ & $18.86 \pm 0.47$ & 2.51 & $19.91 \pm 0.18$ & 0.92 & - & & $16.58 \pm 0.02$ & 0.13 \\
\hline & $\mathrm{K}$ & $15.17 \pm 0.03$ & $22.25 \pm 0.02$ & 0.10 & $26.60 \pm 0.66$ & 2.50 & - & & $18.36 \pm 0.35$ & 1.89 \\
\hline & $\mathrm{L}$ & $14.86 \pm 0.07$ & $20.43 \pm 0.08$ & 0.42 & - & & - & & - & \\
\hline \multirow[t]{2}{*}{ Tea (powder) } & M & $14.24 \pm 0.10$ & $20.55 \pm 0.16$ & 0.04 & $24.58 \pm 0.16$ & 0.66 & $16.95 \pm 0.05$ & & $23.28 \pm 0.16$ & 0.70 \\
\hline & $\mathrm{N}$ & $13.37 \pm 0.12$ & $24.31 \pm 0.19$ & 2.65 & $26.73 \pm 0.04$ & 1.93 & $\mathrm{ND}^{\mathrm{d}}$ & & $19.49 \pm 0.17$ & 0.87 \\
\hline $\begin{array}{l}\text { Total of detected } \\
\text { plant species }\end{array}$ & & & 10 & & 10 & & 1 & & 5 & \\
\hline
\end{tabular}

qRT-PCRs were carried out in triplicate PCR reactions

${ }^{\mathrm{a} P . A . C}$ positive amplification control (18S rRNA)

${ }^{\mathrm{b}} \mathrm{CV}$ coefficient of variation

${ }^{\mathrm{c}}$ No labeling of ingredients

${ }^{\mathrm{d}} N D$ no amplification after 45 cycles

in hazelnut, and Prieto et al. [38] reported that the primer sets for detecting allergen-coding sequences in almond. In the present study, we demonstrated the specificity and sensitivity of four primer sets for detection of four nuts species such as almond, peanut pine nut, and walnut and confirmed their applicability in commercial products, which suggested that the four species-specific primer sets could be successfully applied in various types of foods.

In conclusion, we designed primers for molecular markers in chloroplast DNA, specifically for SNPs and InDels in the matK gene, for the detection of four nut species in commercial products by qRT-PCR. The validity of using the four designed primer sets was verified by qRTPCR using SYBR green. The accuracy, sensitivity, and specificity of the method were successfully tested in 14 processed foods. This molecular marker-based method of identification had higher sensitivity and specificity as well as a shorter analysis time compared to other PCR-based methods, including single PCR and multiplex PCR methods. This method can be used to detect the presence of allergenic species (almonds, peanuts, pine nuts, and walnuts) that were intentionally or unintentionally added to food, thereby aiding in preventing allergic reactions in consumers.
Acknowledgments This research was supported by a Grant (17162MFDS065) from the Ministry of Food and Drug Safety in 2017.

\section{References}

1. Grosso G, Estruch R (2016) Nut consumption and age-related disease. Maturitas 84:11-16

2. Ros E (2010) Health benefits of nut consumption. Nutrients 2:652-682

3. López-Calleja IM, de la Cruz S, Pegels N, González I, Martín R, García T (2014) Sensitive and specific detection of almond (Prunus dulcis) in commercial food products by real-time PCR. LWT Food Sci Technol 56:31-390

4. Costa J, Mafra I, Carrapatoso I, Oliveira MB (2012) Almond allergens: molecular characterization, detection, and clinical relevance. J Agric Food Chem 60(6):1337-1349

5. Wen HW, Borejsza-Wysocki W, DeCory TR, Durst RA (2007) Peanut allergy, peanut allergens, and methods for the detection of peanut contamination in food products. Compr Rev Food Sci Food Saf 6(2):47-58

6. Cabanillas B, Novak N (2015) Allergic reactions to pine nut: a review. Investig Allergol Clin Immunol 25(5):329-333

7. Costa J, Carrapatoso I, Oliveira MBPP, Mafra I (2013) Walnut allergens: molecular characterization, detection and clinical relevance. Clin Exp Allergy 44:319-341

8. de la Cruz S, López-Calleja IM, Alcocer M, González I, Martín R, García T (2013) TaqMan real-time PCR assay for detection of traces of Brazil nut (Bertholletia excelsa) in food products. Food Control 33:105-113 
9. Hourihane J, Aiken R, Briggs R, Gudgeon L, Grimshaw K, DunnGalvin A, Roberts S (2007) The impact of government advice to pregnant mothers regarding peanut avoidance on the prevalence of peanut allergy in United Kingdom children at school entry. J Allergy Clin Immunol 119(5):1197-1202

10. Wen HW, Borejsza-Wysocki W, DeCory TR, Durst RA (2007) Peanut allergy, peanut allergens, and methods for the detection of peanut contamination in food products. Compr Rev Food Sci Food Saf 6(2):47-58

11. Malorny B, Lofstrom C, Wagner M, Kramer N, Hoorfar J (2008) Enumeration of salmonella bacteria in food and feed samples by real-time PCR for quantitative microbial risk assessment. Appl Environ Microbiol 74:1299-1304

12. Overbergh L, Giulietti A, Valckx D, Decallonne R, Bouillon R, Mathieu C (2003) The use of real-time reverse transcriptase PCR for the quantification of cytokine gene expression. J Biomol Tech JBT 14:3-43

13. Pafundo S, Gulli M, Marmiroli N (2009) $\mathrm{SYBR}^{\circledR}$ GreenER $^{\mathrm{TM}}$ realtime PCR to detect almond in traces in processed food. Food Chem 116:811-815

14. Linacero R, Ballesteros I, Sanchiz A, Prieto N, Iniesto E, Martinez Y, Pedrosa MM, Muzquiz M, Cabanillas B, Rovira M, Burbano C, Cuadrado C (2016) Detection by real time PCR of walnut allergen coding sequences in processed foods. Food Chem 202:334-340

15. Brzezinski JL (2006) Detection of cashew nut DNA in spiked baked goods using a real-time polymerase chain reaction method. J AOAC Int 89(4):1035-1038

16. Arlorio M, Cereti E, Coïsson JD, Travaglia F, Martelli A (2007) Detection of hazelnut (Corylus spp.) in processed foods using real-time PCR. Food Control 18:140-148

17. Brzezinski JL (2007) Detection of sesame seed DNA in foods using real-time PCR. J Food Prot 70(4):1033-1036

18. Ferreira T, Farah A, Oliveira TC, Lima IS, Vitrorio F, Oliveira EMM (2016) Using real-time PCR as a tool for monitoring the authenticity of commercial coffees. Food Chem 199:433-438

19. Fuchs M, Cichna-Markl M, Hochegger R (2012) Development and validation of a novel real-time PCR method for the detection of celery (Apium graveolens) in food. Food Chem 130:189-195

20. Hwang SG, Kim JH, Moon JC, Jang CS (2015) Chloroplast markers for detecting rice grain-derived food ingredients in commercial mixed-flour products. Genes Genom 37:1027-1034

21. Kim JH, Moon JC, Kang TS, Kwon KS, Jang CS (2017) Development of cpDNA markers for discrimination between Cynanchum wilfordii and Cynanchum auriculatum and their application in commercial $C$. wilfordii food products. Appl. Biol Chem 60(1):79-86

22. Daniell H, Lin CS, Ming Y, Chang WJ (2016) Chloroplast genomes: diversity, evolution, and applications in genetic engineering. Genome Biol 17:134. https://doi.org/10.1186/s13059-0161004-2

23. Carbonell-Caballero J, Alonso R, Ibañez V, Terol J, Talon M, Dopazo J (2015) A phylogenetic analysis of 34 chloroplast genomes elucidates the relationships between wild and domestic species within the genus Citrus. Mol Biol Evol 32:2015-2035

24. Chen SL, Xiao PG (2010) Molecular evolution and positive Darwinian selection of the chloroplast maturase matK. J Plant Res 123:241-247

25. Valdivia H, Burns M (2010) Sample preparation and DNA extraction for the detection of allergenic nut materials. J Assoc Public Anal 38:01-12

26. Ramakers C, Ruijter JM, Deprez RH, Moorman AF (2003) Assumption-free analysis of quantitative real-time polymerase chainreaction (PCR) data. Neurosci Lett 339:62-66

27. Mazzara M, Hougs L, Zel J, Savini C (2011) Verification of analytical methods for GMO testing when implementing interlaboratory validated methods. European Network of GMO Laboratories (ENGL). https://doi.org/10.2788/88038

28. Bustin SA, Benes V, Garson JA, Hellemans J, Huggett J, Kubista M, Mueller R, Nolan T, Pfaffl MW, Shipley GL, Vandesompele J, Wittwer CT (2009) The MIQE guidelines: minimum information for publication of quantitative real-time PCR experiments. Clin Chem 55:611-622

29. Barthet MM, Hilu KW (2007) Expression of matK: functional and evolutionary implications. Am J Bot 94(8):1402-1412

30. Ince AG, Karaca M, Onus AN, Bilgen M (2005) Chloroplast matK gene phylogeny of some important species of plants. ResearchGate 18(2):157-162

31. Selvaraj D, Sarma RK, Sathishkumar R (2008) Phylogenetic analysis of chloroplast matK gene from Zingiberaceae for plant DNA barcoding. Bioinformation 3(1):24-27

32. Allmann M, Candrian U, Hffelein C, Lthy J (1993) Polymerase chain reaction (PCR): a possible alternative to immunochemical methods assuring safety and quality of food. Detection of wheat contamination in non-wheat food products. Z Lebensm Unters Forsch 196:248-251

33. Clemente A, Chambers SJ, Lodi F, Nicoletti C, Brett GM (2004) Use of the indirect competitive ELISA for the detection of Brazil nut in food products. Food Control 15:65-69

34. Fang Y, Ramasamy RP (2015) Current and prospective methods for plant disease detection. Biosens Basel 4:537-561

35. Peeridogaheh H, Golmohammadi MG, Pourfarzi F (2013) Evaluation of ELISA and Brucellacapt tests for diagnosis of human Brucellosis. Iran J Microbiol 5(1):14-18

36. Yano T, Sakai Y, Uchida K, Nakao Y, Ishihata K, Nakano S, Yamada T, Sakai S, Urisu A, Akiyama H, Maitani T (2007) Detection of walnut residues in processed foods by polymerase chain reaction. Biosci Biotechnol Biochem 71(7):1793-1796

37. Renčová E, Piskatá Z, Kostelníková D, Tremlová B (2014) Simultaneous detection of peanut and hazelnut allergens in food matrices using multiplex PCR method. Acta Vet Brno 83:77-83

38. Prieto $\mathrm{N}$, Iniesto $\mathrm{E}$, Burbano $\mathrm{C}$, Cabanillas $\mathrm{B}$, Pedrosa MM, Rovira M, Rodríguez J, Muzquiz M, Crespo JF, Cuadrado C, Linacero R (2014) Detection of almond allergen coding sequences in processed foods by real time PCR. J Agric Food Chem 62(24):5617-5624 